\title{
Degradation of ortho-toluidine from aqueous solution by the $\mathrm{TiO}_{2} / \mathrm{O}_{3}$ process
}

\author{
Aref Shokri $^{1} \cdot$ Kazem Mahanpoor ${ }^{2}$
}

Received: 15 January 2016/ Accepted: 20 December 2016/Published online: 30 December 2016

(c) The Author(s) 2016. This article is published with open access at Springerlink.com

\begin{abstract}
In this work, the degradation and mineralization of ortho-toluidine (OT) that is one of the constituents of petrochemical wastewater was investigated by the $\mathrm{TiO}_{2} / \mathrm{O}_{3}$ process. The influence of some operational parameters such as concentration of pollutant $\left(30-90 \mathrm{mg} \mathrm{L}^{-1}\right)$, initial $\mathrm{pH}$ and amounts of $\mathrm{TiO}_{2}$ was investigated. A radical mechanism with the formation of an anion radical superoxide radical prior to hydroxyl radical is suggested for describing the interaction between ozone and $\mathrm{TiO}_{2}$. These results were not similar to the ozonation process alone, in which higher $\mathrm{pH}$ had a positive effect on the removal of OT because of the generation of hydroxyl radicals. In optimum $\mathrm{pH}$ for the ozonation and $\mathrm{O}_{3} / \mathrm{TiO}_{2}$ processes, the degradation efficiency of the OT was 89.5 and $96 \%$, respectively, at $60 \mathrm{~min}$ of reaction. Furthermore, it was made clear that in catalytic ozonation, the degradation efficiency of the OT was higher at neutral $\mathrm{pH}$ conditions $(\mathrm{pH}=7)$. The removal of chemical oxygen demand (COD) was increased from $47.5 \%$ (only ozonation) to $73 \%\left(\mathrm{O}_{3} / \mathrm{TiO}_{2}\right)$ after $90 \mathrm{~min}$ of reaction. The kinetics of degradation was pseudo-first order; the degradation and relative mineralization of the OT were calculated by HPLC and COD tests, respectively.
\end{abstract}

Aref Shokri

aref.shokri3@gmail.com

Kazem Mahanpoor

k-mahanpoor@iau-arak.ac.ir

1 Young Researchers and Elite Club, Arak Branch, Islamic Azad University, Arak, Iran

2 Department of Chemistry, Faculty of Science, Arak Branch, Islamic Azad University, Arak, Iran
Keywords $\mathrm{TiO}_{2}$ nanocatalyst - Degradation · Orthotoluidine (OT) · Chemical oxygen demand (COD) . Catalytic ozonation

\section{Introduction}

The wastewater generated from the Karoon Petrochemical Company in Iran contains ortho-toluidine (OT), 2-nitrophenol and other aromatic derivatives. Certain amounts of aromatic components are wasted during a process which contains a wide range of non-biodegradable pollutants that cause environmental problems [1]. $O$-toluidine is probably considered carcinogenic to humans, based on the international agency for research on cancer [2]. The conventional treatment methods have high operational costs, longer reaction time and secondary pollution [3], so the use of advanced oxidation processes (AOPs) is essential.

AOPs such as $\mathrm{UV} / \mathrm{H}_{2} \mathrm{O}_{2}, \mathrm{UV} / \mathrm{O}_{3}, \mathrm{TiO}_{2} / \mathrm{UV}$, Fenton's reagents and catalytic ozonation include the production of non-selective oxidizing agents such as hydroxyl radicals, for the degradation of toxic and refractory pollutants in different wastewaters [4]. Ozone is a powerful oxidant and is used greatly in water treatment process $[5,6]$. But in most cases, it has been reported that ozone cannot degrade organic pollutants completely and sometimes generates toxic intermediates [7].

In these conditions, catalytic ozonation has been attracting increasing attention as a result of its higher efficiency in the degradation and mineralization of organic pollutants and lower negative effect on the nature of water $[8,9]$. Supported, unsupported metals and metal oxides are the most commonly used catalysts for the ozonation of organic pollutants in water. Among various 
semiconductors, titanium dioxide has been recurrently reported as active, inexpensive and nontoxic. It can accelerate the ozonation process for degradation of a wide range of different pollutants [10,11]. The most common applications of titania are in photocatalysis systems; however, it has been proposed as an active catalyst in catalytic ozonation of organic pollutants. $\mathrm{TiO}_{2}$-catalyzed ozonation was more effective for the removal of some pollutant than ozone alone. The detailed and complete mechanism of catalytic ozonation is not clear up to this time and many studies have been done so far, but it is not completely obvious and is one of the gaps of catalytic ozonation. The effect of $\mathrm{TiO}_{2}$ on ozone decomposition to produce hydroxyl radicals was not obvious. Some researchers proposed mechanisms based on non-radical pathway to form hydroxyl radical. A number of mechanisms are offered, but the direct formation of hydroxyl radicals from ozone decomposition on the surface of $\mathrm{TiO}_{2}$ or indirect formation as a result of secondary reactions is still unknown [12]. Rosal et al. $[13,14]$ were investigated the degradation of clofibric acid by catalytic ozonation on titania. It was proposed that the adsorption and the following reaction of pollutants on catalyst sites are responsible for the improvement of catalytic ozonation.

According to the studies of many researchers, there is still a significant shortage of information concerning the role of $\mathrm{TiO}_{2}$ in ozonation reactions, especially about the ozone decomposition reaction [12].

No study has been done on degradation of orthotoluidine by catalytic ozonation up to this time. In this work, degradation of OT as an aromatic pollutant was studied by the $\mathrm{O}_{3} / \mathrm{TiO}_{2}$ process and the effects of $\mathrm{pH}$, initial concentration of OT, amount of $\mathrm{TiO}_{2}$ and the kinetics of the reaction for higher degradation of OT wre investigated.

\section{Experimental}

\section{Materials}

Ortho-toluidine (OT), $\mathrm{HCl}$ and $\mathrm{NaOH}$, potassium iodide and sodium thiosulphate were of reagent grades and supplied from Merck. Titanium dioxide $(P-25,30 \%$ Rutile and $70 \%$ Anatase) purchased from Degussa, Germany, has a BET surface area of $55 \mathrm{~m}^{2} \mathrm{~g}^{-1}$ and an average particle size of $20 \mathrm{~nm}$.

Ozone was produced in an ozone generator fed by dry oxygen and all reagents were used as received without further purification. Distilled water was used throughout this study.

\section{Apparatus}

Experiments were carried out in a semi batch (batch for $\mathrm{TiO}_{2}$ and OT and continuous for ozone) reactor. The pure oxygen, from a pressurized capsule, was entered into an ozone generator $(214 \mathrm{~V}$ and $0.39 \mathrm{~A})$ from the ARDA companies of Iran. The reactor was equipped with a waterflow jacket connected to a thermostat (BW20G model from Korean Company) for adjusting the temperature at $25{ }^{\circ} \mathrm{C}$ in all experiments as shown in Fig. 1. The $\mathrm{pH}$ was measured by the $\mathrm{pH}$ meter PT-10P Sartorius instrument, Germany. The progress in the degradation of the OT was recorded by a high-performance liquid chromatography (Knauer, Germany) equipped with a Spectrophotometer (Platm blue Germany). A reverse phase column was filled with $3 \mu \mathrm{m}$ Separon $\mathrm{C}_{18}$ with $150 \mathrm{~mm}$ length and $4.6 \mathrm{~mm}$ diameter. The isocratic method was used with $\mathrm{pH}$ adjusted to 2.5 , using orthophosphoric acid and a solvent mixture of acetonitrile and deionized water $(60: 40 \% \mathrm{v} / \mathrm{v})$ at a flow rate of $1 \mathrm{~mL} \mathrm{~min}{ }^{-1}$ at room temperature. In all tests, the
Fig. 1 Schematic diagram of the laboratory-scale installation. Notes: 1 pure oxygen, 2 cut off valve, 3 gas flow meter, 4 ozone generator, 5 washing bottle, 6 reactor, 7 magnetic stirrer, 8 ozone diffuser, 9 magnetic bar, 10 sampling port, 11 cooling water supply from thermostat, 12 cooling water return to thermostat

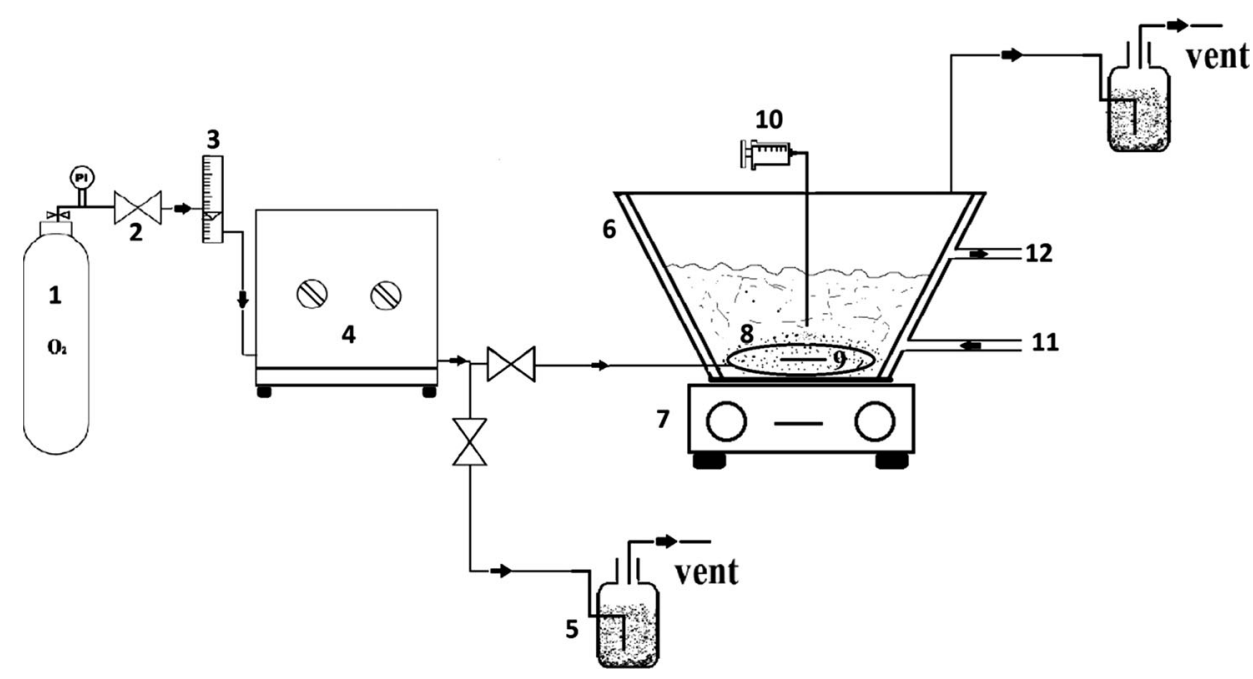


suspension was centrifuged and filtered to collect the catalyst particles.

\section{Catalytic ozonation tests}

About 2 L of aqueous solution containing a known concentration of the OT and nano $\mathrm{TiO}_{2}$ was mixed completely in the reactor. A mixture of $\mathrm{O}_{3} / \mathrm{O}_{2}$ was produced by the ozone generator and entered from the bottom of the reactor by a porous diffuser for mixing well, saturating the solution with $\mathrm{O}_{3}$, better mass transfer and reaction between ozone, $\mathrm{TiO}_{2}$ and the pollutant. The concentration of gaseous ozone was measured by the iodometric method using $2 \%$ neutral buffered potassium iodide for ozone trapping and sodium thiosulfate as a titrant [15]. The flow rate of the $\mathrm{O}_{3} / \mathrm{O}_{2}$ mixture was kept constant at $0.4 \mathrm{~L} \mathrm{~min}^{-1}$, based on the previous studies and initial tests, having an ozone concentration of $16.6 \mathrm{mg} \mathrm{L}^{-1}$. To know the amount of ozone consumed, the reactor outlet gas was bubbled through a KI ( $2 \% \mathrm{w})$ tamponed solution for determining the ozone not reacted, while the potassium iodide solution reacted with the excess ozone based on the following equation (Eq. 1):

$\mathrm{O}_{3}+2 \mathrm{KI}+\mathrm{H}_{2} \mathrm{O} \rightarrow \mathrm{I}_{2}+2 \mathrm{KOH}+\mathrm{O}_{2}$.

The produced iodine was titrated by standard sodium thiosulphate in the presence of starch as an indicator. The amounts of not reacted and reacted ozone, and the value of ozone in the tail gas were determined correspondingly. The residual of ozone in aqueous solution was estimated by a spectrophotometer using the indigo method [16].

$\mathrm{TiO}_{2}$ particles were dispersed and suspended in the solution as the ozone gas entered into the reactor. Samples were withdrawn at different intervals and filtered to remove the $\mathrm{TiO}_{2}$ particles. The concentration of OT was determined by spectrophotometry at two peaks, 230 and $280 \mathrm{~nm}$. The HPLC and spectrophotometry methods (especially in $280 \mathrm{~nm}$ ) gave similar results and the difference between them was little, which was corrected. But in acidic $\mathrm{pH}$ (lower than 4 ), the results of spectrophotometry cannot be related to HPLC, because the UV peaks of OT were destroyed in very acidic $\mathrm{pH}$. In this condition, only HPLC should be employed. The experiments were carried out in the $\mathrm{pH}$ range of $4-10$. The $\mathrm{pH}$ was adjusted only at the beginning of the reaction by adding $\mathrm{NaOH}(0.1 \mathrm{M})$ or $\mathrm{HCl}(0.1 \mathrm{M})$. A slight decrease in $\mathrm{pH}$ occurred based on the production of mineral acids.

COD was measured by the standard closed reflux and colorimetric method [17] and the absorbance of samples for COD was measured by a spectrophotometer at $600 \mathrm{~nm}$.

The removal percent of OT and COD as a function of reaction time is given by the following equations (Eqs. 23):
Removal of OT $(\%)=\left(\frac{[\mathrm{OT}]_{0}-[\mathrm{OT}]_{t}}{[\mathrm{OT}]_{0}}\right) \times 100$

Removal of $\operatorname{COD}(\%)=\left(\frac{[\mathrm{COD}]_{0}-[\mathrm{COD}]}{[\mathrm{COD}]_{0}}\right) \times 100$,

where $[\mathrm{OT}]_{0}$ and $[\mathrm{COD}]_{0}$ are the initial concentrations of OT and COD at the start of the reaction, and [OT] and [COD] are the concentrations of the OT and amount of COD at time $t$, respectively.

\section{Results and discussion}

\section{Effect of pH on ozonation}

The degradation of ozone in aqueous solution depends on $\mathrm{pH}$ strongly, and it enhances with the increase in $\mathrm{pH}$ [18]. The experiments were carried out at $\mathrm{pH}$ values of $4,6,8,9$ and 10 and, as seen from Fig. 2, the results showed that the removal efficiency increased from 43 to $89.5 \%$ in $60 \mathrm{~min}$ of reaction as the $\mathrm{pH}$ increased from 4 to 9 and then decreased to $86 \%$. So, the optimum $\mathrm{pH}$ during this process was 9.

At $\mathrm{pH}=4$, the formation of hydroxyl radicals was very low, so only slight radical reactions occurred. However, direct molecular ozonolysis was highly predominant and ozone reacted with the pollutant directly and the double bonds of the OT ring seemed to be destroyed by ozone. Hydroxyl radicals were strong oxidants that originated from the reaction of hydroxide ions with ozone at high $\mathrm{pH}$ and initiated the chain oxidation reaction of ozone, which was non-selective and very fast. At $\mathrm{pH}=10$, radical scavenging occurred because of a greater number of

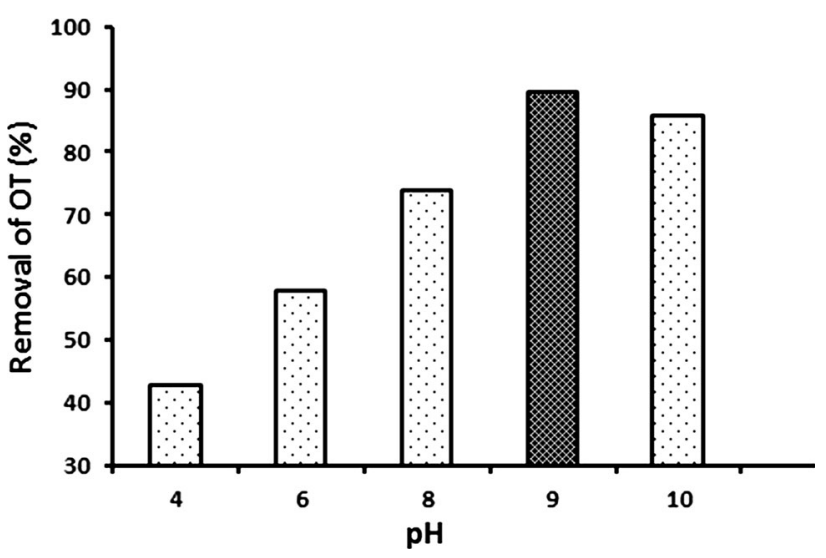

Fig. 2 Effect of $\mathrm{pH}$ on ozonation of OT $\left(\left[\mathrm{O}_{3}\right]_{\mathrm{o}}=16.6 \mathrm{mg} \mathrm{L}^{-1}\right.$, $[\mathrm{OT}]_{\mathrm{o}}=50 \mathrm{mg} \mathrm{L}^{-1}$ ) 
hydroxide ions and consequently there was more hydroxyl radical production [19].

\section{Effect of catalyst amount on the $\mathrm{TiO}_{2} / \mathrm{O}_{3}$ process}

The effect of catalyst extent on the degradation of OT is presented in Fig. 3. In the non-catalytic ozonation process, the ordinary conversion of the OT was achieved because the action of free radicals created from the self-decomposition of ozone was poor. It is acceptable that ozonation of water also leads to the production of hydroxyl radicals through ozone disintegration [20]. The degradation efficiency of the OT was significantly increased in the presence of both ozone and catalyst. An exceptional feature of nano $\mathrm{TiO}_{2}$ is its extremely high surface area. It is obvious that the degradation of the OT was based on the action of some ozone-absorbed species or free radicals produced perhaps on the catalyst surface or in the aqueous solution. Catalyst amounts employed a positive effect on OT removal in $\mathrm{TiO}_{2} / \mathrm{O}_{3}$ process. But as depicted in Fig. 3, the removal efficiency was increased from 80.5 to $93.5 \%$ by the increase in catalyst dose from 0.6 to $1.2 \mathrm{~g} \mathrm{~L}^{-1}$. A further increase in catalyst amounts to $1.8 \mathrm{~g} \mathrm{~L}^{-1} \mathrm{did}$ not yield any significant increase in the degradation rate. The difference between the removal efficiency of OT at 1.2 and $1.5 \mathrm{~g} \mathrm{~L}^{-1}$ of $\mathrm{TiO}_{2}$ was very low, So, $1.2 \mathrm{~g} \mathrm{~L}^{-1}$ of catalyst was obtained as an optimum concentration of $\mathrm{TiO}_{2}$ from an economic point of view and other experiments were performed in this concentration of catalyst.

\section{Effect of $\mathrm{pH}$ on the $\mathrm{TiO}_{2} / \mathrm{O}_{3}$ process}

In the $\mathrm{TiO}_{2} / \mathrm{O}_{3}$ system, $\mathrm{pH}$ had two direct effects on the process: one is ozone decomposition and the other is the surface charge and characteristics of the $\mathrm{TiO}_{2}$ nanocatalyst, which has a direct influence on the adsorption of pollutant molecules [21, 22]. The point of zero charge (PZC) of $\mathrm{TiO}_{2}$

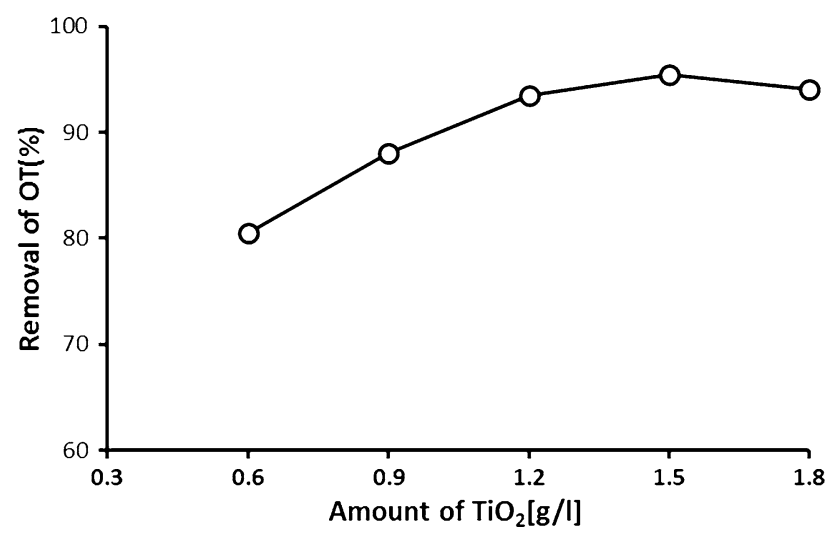

Fig. 3 Catalytic ozonation of OT with various catalyst doses $\left(\left[\mathrm{O}_{3}\right]_{\mathrm{o}}=16.6 \mathrm{mg} \mathrm{L}^{-1}, \quad[\mathrm{OT}]_{\mathrm{o}}=50 \mathrm{mg} \mathrm{L}^{-1}, \quad \mathrm{pH}=6\right.$, time $=$ $60 \mathrm{~min})$

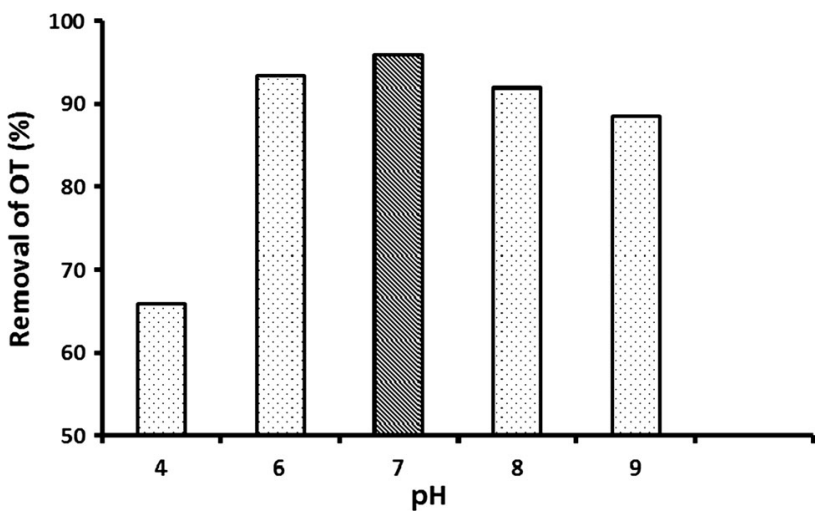

Fig. 4 Effect of $\mathrm{pH}$ on the $\mathrm{TiO}_{2} / \mathrm{O}_{3}$ process $\left(\left[\mathrm{TiO}_{2}\right]=1.2 \mathrm{~g} \mathrm{~L}^{-1}\right.$, $\left[\mathrm{O}_{3}\right]_{\mathrm{o}}=16.6 \mathrm{mg} \mathrm{L}^{-1},[\mathrm{OT}]_{\mathrm{o}}=50 \mathrm{mg} \mathrm{L}^{-1}$, time $\left.=60 \mathrm{~min}\right)$

was reported as 6.6 [23] and this factor affected the absorption of the pollutant on the catalyst and was determined by potentiometric titration as explained by Halter [24]. Organic pollutants in neutral state may be adsorbed on the surface of the catalyst if the surface is not charged near the PZC of the catalyst [25].

The effect of $\mathrm{pH}$ on the $\mathrm{TiO}_{2} / \mathrm{O}_{3}$ process is shown in Fig. 4. From the experimental results, it was clear that during treatment, the best results were obtained at a neutral $\mathrm{pH}$. After $60 \mathrm{~min}$, the degradation efficiency of OT was $96 \%$ in neutral condition $(\mathrm{pH}=7)$, while in the solutions with $\mathrm{pH} 4,6,8$ and 9 it was about $66,93,92$, and $88.5 \%$, respectively. The surface properties and the electrostatic interactions between $\mathrm{TiO}_{2}$ and hydroxide ions in the solution were the main factors affecting the degradation of OT.

\section{The effect of the initial concentration of OT on the removal efficiency}

The effect of the initial concentration of OT on the efficiency of degradation in $\mathrm{TiO}_{2} / \mathrm{O}_{3}$ was investigated over the concentration range from 30 to $90 \mathrm{mg} \mathrm{L}^{-1}$ and the results are shown in Fig. 5. The results revealed that the rate of removal was increased slightly from 94.5 to $96 \%$ with an increase in OT dosage from 30 to $50 \mathrm{mg} \mathrm{L}^{-1}$, but with an increase in its initial concentration from 50 to $90 \mathrm{mg} \mathrm{L}^{-1}$, the removal efficiency of the OT was reduced significantly. When the initial dosage of the pollutant was high (90 $\mathrm{m} \mathrm{L} \mathrm{L}^{-1}$ ), the number of available active sites was decreased and the generation of hydroxyl radicals was reduced by OT molecules, because of their competitive adsorption on the $\mathrm{TiO}_{2}$ surface. Only $55.5 \%$ of the pollutant was degraded after 90 min of reaction.

With an increase in the initial concentration of OT, active agents such as hydroxyl radicals that originated from the process were decreased because they reacted with a large number of pollutant molecules [26]. When the 


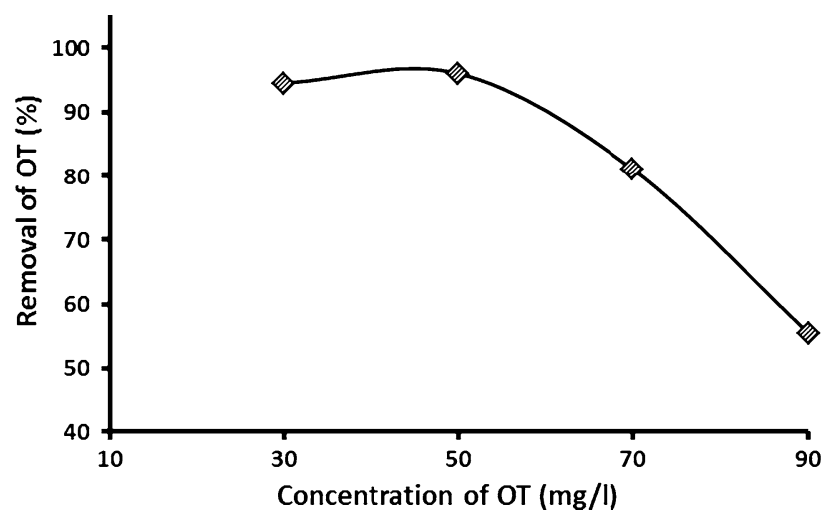

Fig. 5 Effect of initial dosage of OT on the degradation efficiency in the $\mathrm{TiO}_{2} / \mathrm{O}_{3}$ process $\left(\mathrm{pH}=7,\left[\mathrm{TiO}_{2}\right]=1.2 \mathrm{~g} \mathrm{~L}^{-1}\right.$, time $\left.=60 \mathrm{~min}\right)$

concentration of OT was increased, the surface of $\mathrm{TiO}_{2}$ was covered by pollutant molecules instead of ozone and subsequent production of the active agents for destroying the pollutant decreased. However, when the number of pollutant molecules was very low, their collisions with active sites were decreased and the degradation efficiency was reduced [27].

\section{Degradation of OT by the $\mathrm{TiO}_{2} / \mathrm{O}_{3}$ and $\mathrm{O}_{3}$ processes}

Ernst et al. [28] proposed that the dissolved ozone is adsorbed first on the catalyst surface during the catalytic ozonation with $\mathrm{Al}_{2} \mathrm{O}_{3}$, and then degraded quickly; according to the existence of hydroxyl surface groups, $\mathrm{O}_{2}^{--}$ was produced and then resulted in the production of hydroxyl radicals from a series of reactions. Also, Zhang et al. [29] recommended that $\mathrm{O}_{2}^{--}$and hydroxyl radicals were created by the ozone molecule with the hydroxyl group as catalyst. In this study, the dissolved molecular ozone was adsorbed on the $\mathrm{TiO}_{2}$ surface at first and then decayed into $\mathrm{O}_{2}^{--}$and $\mathrm{OH}^{\bullet}$ rapidly due to the presence of hydroxyl surface groups on the catalyst (Eqs. 6, 7). Furthermore, the produced $\mathrm{O}_{2}^{--}$could promote molecular ozone to decompose into hydroxyl radicals. Then the OT adsorbed on the surface of the $\mathrm{TiO}_{2}$ would be degraded by $\mathrm{OH}$ and molecular ozone (Eqs. 4, 5). As ozonation along with $\mathrm{TiO}_{2}$ can happen through either direct reaction with molecular ozone or indirect reaction with the produced hydroxyl radicals, the removal of the OT can be symbolized by the following simple reactions (Eqs. 4-9) [30]:

$\mathrm{O}_{3}+\mathrm{OT} \rightarrow$ intermediate product,

$\mathrm{OH}+\mathrm{OT} \rightarrow$ intermediate product,

$\mathrm{O}_{3}+\mathrm{OH}^{-} \rightarrow \mathrm{HO}_{2}+\mathrm{O}_{2}^{--}$,

$\mathrm{O}_{3}+\mathrm{HO}_{2} \rightarrow \mathrm{OH}^{-}+2 \mathrm{O}_{2}$
$\mathrm{O}_{3}+\mathrm{OH}^{\cdot} \rightarrow \mathrm{HO}_{2}+\mathrm{O}_{2}$,

$2 \mathrm{HO}_{2} \rightarrow \mathrm{H}_{2} \mathrm{O}_{2}+\mathrm{O}_{2}$.

It has been suggested that ozone can be adsorbed on a catalyst surface to yield different oxidizing species [31]. According to the proposed mechanism, ozone and organic molecules were adsorbed on the catalyst surface concurrently, ozone degraded on the metallic sites and produced the surface bond radical $\left(\mathrm{O}_{2}^{-}\right)$, which are more reactive than ozone and lead to the production of hydroxyl radicals. Oxidation continues through some oxidized intermediates gradually, while $\mathrm{O}_{2}^{--}$radicals are continuously produced by dissolving ozone that is transferred to the catalyst surface. The attraction of the oxidation products to the surface of the catalyst reduces the repulsion of the final degradation products from the catalyst surface [32].

As it can be seen from Fig. 6, experiments were performed in $90 \mathrm{~min}$ for the comparative study of different processes at their optimum $\mathrm{pH}$. Only 5\% of OT disappeared when in contact with $\mathrm{TiO}_{2}$ alone at $\mathrm{pH}=7$, as a result of the pollutant adsorption on the surface of the nanocatalyst at a catalyst concentration of $1.2 \mathrm{~g} \mathrm{~L}^{-1}$. Therefore, the OT removal rate of the ozone along with $\mathrm{TiO}_{2}$ was higher than the sum of the separate influences of single adsorption and single ozonation.

In runs with $\mathrm{TiO}_{2} / \mathrm{O}_{3}$ and $\mathrm{O}_{3}$ processes, 96 and $89 \%$ of OT was removed, respectively. The corresponding results indicated that the presence of $\mathrm{TiO}_{2}$ can accelerate the degradation of OT rather than ozone oxidation alone. In addition, $\mathrm{TiO}_{2}$ has the ability to enhance the decomposition of ozone and promote the formation of hydroxyl radicals. According to preliminary experiments, about $1.2 \mathrm{~g} \mathrm{~L}^{-1}$ of $\mathrm{TiO}_{2}$ was used because it can initiate the degradation of OT, and at high dosage of catalysts the aggregation of $\mathrm{TiO}_{2}$ particles occurred.

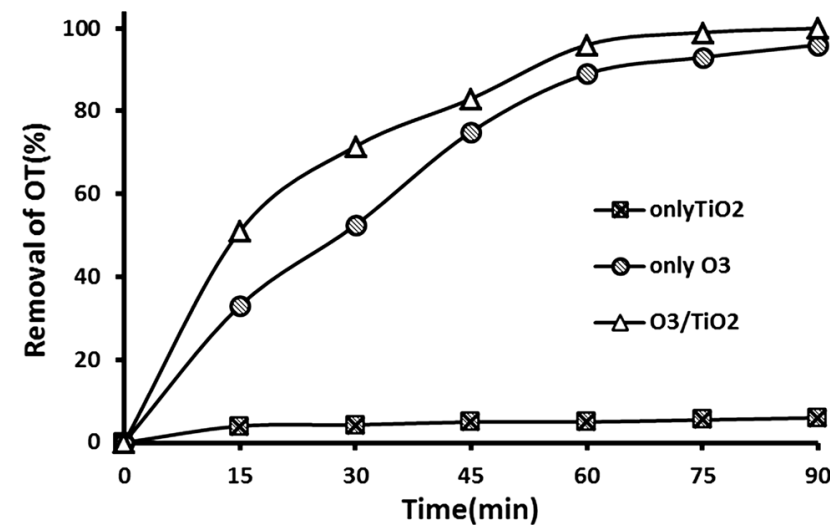

Fig. 6 Degradation of OT during ozonation and catalytic ozonation $\left([\mathrm{OT}]_{\mathrm{o}}=50 \mathrm{mg} \mathrm{L}^{-1},\left[\mathrm{O}_{3}\right]_{\mathrm{o}}=16.6 \mathrm{mg} \mathrm{L}^{-1}\right.$, optimum $\mathrm{pH}$ for each process, $\left[\mathrm{TiO}_{2}\right]=1.2 \mathrm{~g} \mathrm{~L}^{-1}$ ) 


\section{Reusability of the $\mathrm{TiO}_{2}$ catalyst}

The reusability of the $\mathrm{TiO}_{2}$ catalyst was investigated for degradation of OT. The $\mathrm{TiO}_{2}$ particles were separated from the solution by filtration, then washed with distilled water and regenerated by drying and heating at $150{ }^{\circ} \mathrm{C}$ for $2 \mathrm{~h}$. At high temperatures, the adsorbed molecules on the surface were removed and some of the active sites were released.

An equal amount of regenerated catalyst was used for the degradation of OT at optimum experimental condition. After three runs of the experiment, the degradation efficiency decreased to 92,84 and $66 \%$. The following are the reasons for this decrease in efficiency: (I) adsorption of intermediates and side products of the process in the active sites and on the surface of the catalyst leads to decrease in the degradation efficiency [33]; (II) as Ti leaching occurred, the active sites on the catalyst surface were removed and the activity of the remaining catalyst was decreased; (III) the structure and morphology of the catalyst matrix was deformed gradually by continuous heating in the regeneration process. It was clear that using ozone along with $\mathrm{TiO}_{2}$ prevented the catalyst deactivation to some extent [34].

\section{Removal of COD}

The removal efficiency of COD was studied by $\mathrm{O}_{3}$ and $\mathrm{O}_{3} /$ $\mathrm{TiO}_{2}$ processes at optimum $\mathrm{pH}$ for the degradation of each process. The removal of COD through the degradation of OT in 90 min is shown in Fig. 7.

In the $\mathrm{O}_{3} / \mathrm{TiO}_{2}$ process, the amount of $\mathrm{COD}$ was decreased sharply during the first $45 \mathrm{~min}$ and then decreased slowly. After 90 min of treatment, in the $\mathrm{O}_{3}$ and $\mathrm{O}_{3} / \mathrm{TiO}_{2}$ process, the removal of COD was 47.5 and $73 \%$, respectively.

It is clear that ozonation alone is a slow process, but the $\mathrm{O}_{3} / \mathrm{TiO}_{2}$ reaction is a rapid one. So, it can be inferred that

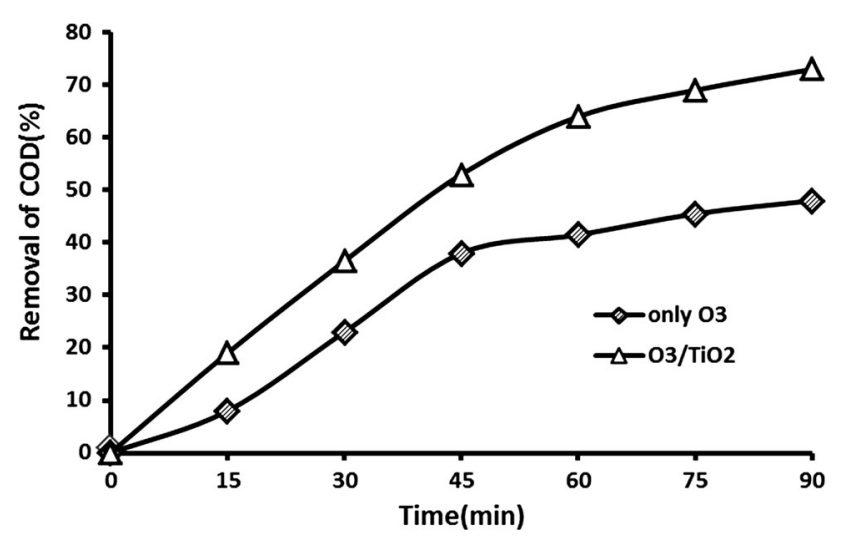

Fig. 7 Removal of COD in ozonation and catalytic ozonation of OT during $90 \mathrm{~min}\left(\mathrm{pH}=9\right.$ in $\mathrm{O}_{3}$ and $\mathrm{pH}=7$ in $\mathrm{O}_{3} / \mathrm{TiO}_{2}$ process, $\left[\mathrm{TiO}_{2}\right]=1.2 \mathrm{~g} \mathrm{~L}^{-1},\left[\mathrm{O}_{3}\right]_{\mathrm{o}}=16.6 \mathrm{mg} \mathrm{L}^{-1},[\mathrm{OT}]_{\mathrm{o}}=50 \mathrm{mg} \mathrm{L}^{-1}$ )
OT was mineralized partially and some degradation intermediates were created during the process; OT cannot be totally mineralized even by the $\mathrm{O}_{3} / \mathrm{TiO}_{2}$ methods [35].

\section{Kinetic study in the degradation of OT with the $\mathrm{O}_{3} /$ nano- $\mathrm{TiO}_{2}$ process}

The studies of other researchers established that the production of hydroxyl radicals according to the ozone decomposition on the surface of the catalyst was responsible for the enhancement of catalytic ozonation [36, 37]. But when the $\mathrm{Mn}-\mathrm{Ce}-\mathrm{O}$ catalyst was employed to improve the removal efficiency of phenolic acids, a dissimilar deduction was obtained from the study of Martins and Quinta-Ferreira [38]; in that case of the existence of radical scavengers had no influence on the catalytic ozonation efficiency. This finding showed that the reaction of their study was not a radical mechanism.

However, in our study, a kinetic study for degradation of $\mathrm{OT}$ in the $\mathrm{O}_{3} / \mathrm{TiO}_{2}$ process was performed at optimum $\mathrm{pH}$ $(\mathrm{pH}=7)$. From the mentioned studies, it can be inferred that the probable mechanism for the catalytic ozonation comprised an indirect oxidation reaction with hydroxyl radicals and a direct oxidation reaction after the ozone and OT adsorbed on the surface of $\mathrm{TiO}_{2}$. The kinetic relation for degradation of the OT by the pointed out process can be represented as:

$\frac{-d[\mathrm{OT}]}{d t}=k o_{3}[\mathrm{OT}]\left[\mathrm{TiO}_{2}\right]\left[O_{3}\right]+k_{\mathrm{OH}}[\mathrm{OT}]\left[\mathrm{TiO}_{2}\right][\mathrm{OH} \cdot]$,

where $[\mathrm{OT}],\left[\mathrm{O}_{3}\right],[\mathrm{OH} \cdot]$ and $\left[\mathrm{TiO}_{2}\right]$ are the concentrations of OT, ozone, hydroxyl radicals and $\mathrm{TiO}_{2}$, respectively. Moreover $k_{\mathrm{OH}}$. and $\mathrm{ko}_{3}$ are the rate constants of OT with hydroxyl radicals and ozone. At neutral $\mathrm{pH}$ values, the nonselective reactions of hydroxyl radicals with OT were predominant [35], so the kinetic equation can be written as:

$\frac{-d[\mathrm{OT}]}{d t}=k_{\mathrm{OH} \cdot}[\mathrm{OT}]\left[\mathrm{TiO}_{2}\right]\left[\mathrm{OH}^{\bullet}\right]$.

In this process, the OT was degraded by reaction with $\mathrm{TiO}_{2}$ and $\mathrm{O}_{3}$, and the ratio of the concentration of OT to $\mathrm{O}_{3}, \mathrm{OH}$. or $\mathrm{TiO}_{2}$ was low; so the concentration of hydroxyl radicals and catalyst can be considered constant. In these conditions, only the concentration of the OT was changed and the reaction was pseudo-first order [39]. So, the equation rate can be shown as:

$\frac{-d[\mathrm{OT}]}{d t}=k_{\mathrm{OH}}^{\prime}[\mathrm{OT}]$,

where $k_{\mathrm{OH}}^{\prime}$. is a pseudo-first-order rate reaction of OT with hydroxyl radicals originating from the $\mathrm{O}_{3} /$ nano- $\mathrm{TiO}_{2}$ process. The integration of Eq. (12) results in: 


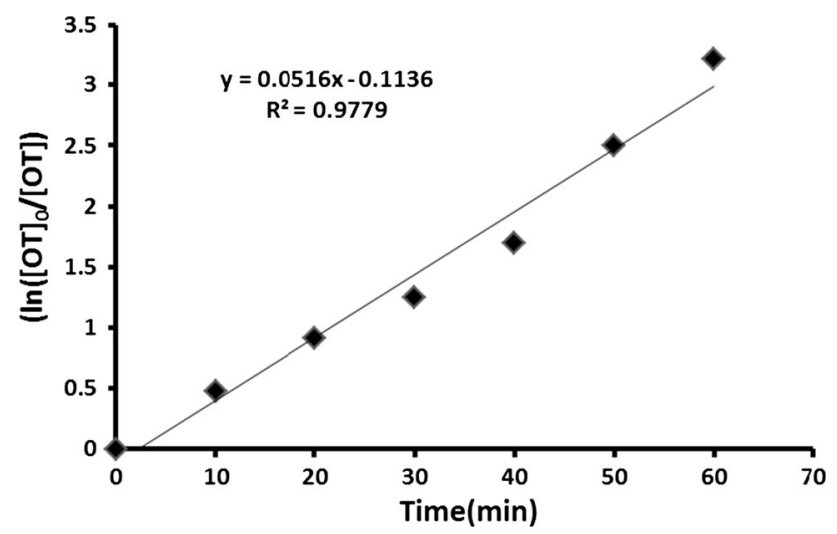

Fig. 8 The curve of $\ln \frac{[\mathrm{OT}]_{0}}{[\mathrm{OT}]_{t}}$ versus reaction time in the $\mathrm{O}_{3} / \mathrm{TiO}_{2}$ process $\left(\mathrm{pH}=7,\left[\mathrm{TiO}_{2}\right]=1.2 \mathrm{~g} \mathrm{~L}^{-1},\left[\mathrm{O}_{3}\right]=16.6 \mathrm{mg} \mathrm{L}^{-1}\right.$ and $\left.[\mathrm{OT}]_{\mathrm{o}}=50 \mathrm{mg} \mathrm{L}^{-1}\right)$

$-\ln \frac{[\mathrm{OT}]}{[\mathrm{OT}]_{0}}=k_{\mathrm{OH}}^{\prime} \cdot t$

where $[\mathrm{OT}]$ and $[\mathrm{OT}]_{0}$ are the concentration of OT at time $=\mathrm{t}$ and time $=0$, respectively. As seen from Fig. 8, the term $\ln \frac{[\mathrm{OT}]_{0}}{[\mathrm{OT}]_{t}}$ versus reaction time was plotted, and after linear regression analysis the apparent first-order rate constants $\left(k_{\mathrm{OH}}^{\prime}=51.6 \times 10^{-3} \mathrm{~min}^{-1}\right)$ and half-life of degradation reaction $\left(t_{1 / 2}=13.4 \mathrm{~min}\right.$ were determined (Eq. 13). By comparing the rate constant of this study with the previous research $\left(k=54.8 \times 10^{-3} \mathrm{~min}^{-1}\right)$ [40], it is obvious that the rate constant depends on the type and initial concentration of the pollutant, dosage of ozone, features of the reactor and catalyst characteristics.

\section{Conclusion}

The combination of ozone and $\mathrm{TiO}_{2}$ catalyst has a significant effect on the removal of OT in aqueous solutions, and based on the experimental results the following conclusions are obtained:

The nanocatalyst of $\mathrm{TiO}_{2}$ accelerates the decomposition of ozone under neutral condition $(\mathrm{pH}=7)$. In the $\mathrm{TiO}_{2} / \mathrm{O}_{3}$ system, the $\mathrm{pH}$ has two direct effects on the process, one is ozone decomposition and the other is on the surface charge and characteristic of the $\mathrm{TiO}_{2}$ nanocatalyst. The oxidation efficiency of OT is higher at neutral $\mathrm{pH}$ than at alkaline or acidic ones. The removal of OT is 96 and $89 \%$ at $60 \mathrm{~min}$ of reaction; also the removal of $\mathrm{COD}$ is 73 and $47.5 \%$ after $90 \mathrm{~min}$ of reaction in the $\mathrm{TiO}_{2} / \mathrm{O}_{3}$ and $\mathrm{O}_{3}$ processes, respectively. The adsorption and the following reaction of OT on $\mathrm{TiO}_{2}$ sites are responsible for the improvement of ozonation rate observed in catalytic runs. The OT removal rate in the ozone along with $\mathrm{TiO}_{2}$ was higher than the sum of the separate influences of single adsorption of catalyst
(5\%) at $1.2 \mathrm{~g} \mathrm{~L}^{-1}$ and single ozonation, especially in COD removal efficiencies (47.5 and $73 \%$ in $\mathrm{O}_{3}$ and $\mathrm{TiO}_{2} / \mathrm{O}_{3}$ process). According to kinetic studies, it is clear that in $\mathrm{O}_{3} / \mathrm{TiO}_{2}$ process the rate equation for degradation of the OT is pseudo-first-order and after linear regression, $R^{2}$ is obtained at 0.9779 and a little deviation from 1 , is because of assuming this concept that direct and selective reactions of ozone are negligible in neutral conditions. These experimental results established the hypothesis that the removal of OT by the $\mathrm{O}_{3} /$ nano- $\mathrm{TiO}_{2}$ process followed a radical-type mechanism. The proposed mechanism mentioned that ozone and organic molecules are adsorbed on the catalyst surface simultaneously, ozone degrades and produce the surface bond radicals $\left(\mathrm{O}_{2}^{-}\right)$, that they are more reactive than ozone and lead to the production of $\mathrm{OH}$. and hydroxyl radical was represented in kinetic equations.

Acknowledgements The authors wish to thank the Islamic Azad University of Arak, Iran, for the financial support.

Open Access This article is distributed under the terms of the Creative Commons Attribution 4.0 International License (http://crea tivecommons.org/licenses/by/4.0/), which permits unrestricted use, distribution, and reproduction in any medium, provided you give appropriate credit to the original author(s) and the source, provide a link to the Creative Commons license, and indicate if changes were made.

\section{References}

1. Christie RM (2011) Color chemistry. Royal Society of Chemistry, London, p 2011

2. Ferlay J, Parkin DM, Steliarova-foucher E (2010) Estimates of cancer incidence and mortality in Europe in 2008. Eur J Cancer 46:765-781

3. Yahiat S, Fourcade F, Brosillon S, Amrane A (2011) Photo catalysis as a pre-treatment prior to a biological degradation of cyproconazole. Desalination 281:61-67

4. Gharbani P, Khosravi M, Tabatabaii SM, Zare K, Dastmalchi S, Mehrizad A (2010) Degradation of trace aqueous 4-chloro-2-nitrophenol occurring in pharmaceutical industry wastewater by ozone. Int J Environ Sci Technol 7:377-384

5. Ternes TA, Meisenheimer M, Mc Dowell D, Sacher F, Brauch HJ (2002) Removal of pharmaceuticals during drinking water treatment. Environ Sci Technol 36:3855-3863

6. Hua W, Bennett ER, Letcher RJ (2006) Ozone treatment and the depletion of detectable pharmaceuticals and atrazine herbicide in drinking water sourced from the upper Detroit River. Water Res 40:2259-2266

7. Kasprzyk B, Nawrocki J (2002) Preliminary results on ozonation enhancement by a perfluorinated bonded alumina phase. Ozone Sci Eng 24:63-68

8. Sui M, Xing S, Sheng L, Huang S, Guo H (2012) Heterogeneous catalytic ozonation of ciprofloxacin in water with carbon nanotube supported manganese oxides as catalyst. J Hazard Mater 15:227-236

9. Gracia R, Cortes S, Sarasa J, Ormad P, Ovelleiro JL (2000) $\mathrm{TiO}_{2^{-}}$ catalysed ozonation of raw Ebro river water. Water Res 34:1525-1532 
10. Farbod M, Khademalrasool M (2011) Synthesis of $\mathrm{TiO}_{2}$ nano particles by a combined sol-gel ball milling method and investigation of nano particle size effect on their photo catalytic activities. Powder Technol 214:344-348

11. Saliby I, Okour Y, Shon HK, Kandasamy J, Lee WE, Kim J (2012) $\mathrm{TiO}_{2}$ nano particles and nano fibres from $\mathrm{TiCl}_{4}$ flocculated sludge: characterisation and photo catalytic activity. J Ind Eng Chem 18:1033-1038

12. Yang Y, Ma J, Qin Q, Zhai X (2007) Degradation of nitrobenzene by nano- $\mathrm{TiO}_{2}$ catalyzed ozonation. J Mol Catal A: Chem 267:41-48

13. Rosal R, Gonzalo MS, Rodriguez A, Garcia-Calvo E (2009) Ozonation of clofibric acid catalyzed by titanium dioxide. J Hazard Mater 169:411-418

14. Rosal R, Gonzalo MS, Boltes K, Leton P, Vaquero JJ, GarciaCalvo E (2009) Identification of intermediates and assessment of ecotoxicity in the oxidation products generated during the ozonation of clofibric acid. J Hazard Mater 172:1061-1068

15. Langlais B, Reckhow DA, Brink DR (1991) Ozone in water treatment: application and engineering. Lewis Publishers, Michigan- USA

16. Bader H, Hoigne AJ (1981) Determination of ozone in water by the indigo method. Water Res 15:449-456

17. APHA (1999) standard methods for examination of water and wastewater, twentieth edn. American Public Health Association, Washington

18. Beltran FJ (2004) Ozone reaction kinetics for water and wastewater systems. Lewis Publishers, Boca Raton

19. Muthukumar M, Sargunamani D, Selvakumar N, Rao VJ (2004) Optimization of ozone treatment for color and COD removal of acid dye effluent using central composite design experiment. Dyes Pigments 64:127-134

20. Hoigne J, Bader H (1983) Rate constants of reactions of ozone with organic and inorganic compounds in water-I: non-dissociating organic compounds. Water Res 17:173-183

21. Stumm W, Morgan JJ (1981) Aquatic chemistry:chemical equilibria and rates in natural waters. John Wiley \& Sons Inc, New York

22. Rodea-Palomares I, Petre A, Boltes K et al (2010) Application of the combination index (CI)-isobologram equation to study the toxicological interactions of lipid regulators in two aquatic bioluminescent organisms. Water Res 44:427-438

23. Rosal R, Rodriguez A, Gonzalo MS, Garcia-Calvo E (2008) Catalytic ozonation of naproxen and Carbamazepine on titanium dioxide. Appl Catal B Environ 4:48-57

24. Halter WE (1999) Surface acidity constants of a- $\mathrm{Al}_{2} \mathrm{O}_{3}$ between 25 and $70{ }^{\circ} \mathrm{C}$. Geochim Cosmochim Acta 63:3077-3085
25. Kasprzyk-Hordern B, Ziolek M, Nawrocki J (2003) Catalytic ozonation and methods of enhancing molecular ozone reactions in water treatment. Appl Catal B Environ 46:639-669

26. Nezamzadeh-Ejhieh A, Amiri M (2013) CuO supported clinoptilolite towards solar photo catalytic degradation of $P$ aminophenol. Powder Technol 235:279-288

27. Shokri A, Mahanpoor K, Soodbar D (2016) Degradation of 2-nitrophenol from petrochemical wastewater by $\mathrm{UV} / \mathrm{NiFe}_{2} \mathrm{O}_{4} /-$ clinoptilolite process. Fresen Environ Bull 25:500-508

28. Ernst M, Lurot F, Schrotter JC (2004) Catalytic ozonation of refractory organic model compounds in aqueous solution by aluminum oxide. Appl Catal B Environ 47:15-25

29. Zhang T, Ma J (2008) Catalytic ozonation of trace nitrobenzene in water with synthetic goethite. J Mol Catal A: Chem 279:82-89

30. Guzman-Perez CA, Soltan J, Robertson J (2011) Kinetics of catalytic ozonation of atrazine in the presence of activated carbon. Sep Purif Technol 79:8-14

31. Beltran FJ, Rivas FJ, Montero R (2002) Catalytic ozonation of oxalic acid in an aqueous $\mathrm{TiO}_{2}$ slurry reactor. Appl Catal B Environ 39:221-231

32. Logeman FP, Annee JHJ (1997) Water treatment with a fixed bed catalytic ozonation process. Water Science Technol 35:353-360

33. Shokri A, Mahanpoor K, Soodbar D (2005) Evaluation of a modified $\mathrm{TiO}_{2}\left(\mathrm{GO}-\mathrm{B}-\mathrm{TiO}_{2}\right)$ photo catalyst for degradation of 4-nitrophenol in petrochemical wastewater by response surface methodology based on the central composite design. J Environ Chem Eng. 4:585-598

34. Crabtree RH (2011) Resolving heterogeneity problems and impurity artifacts in operationally homogeneous transition metal catalysts. Chem Rev 112:1536-1554

35. Goi A, Trapido M, Tuhkanen T (2004) A study of toxicity, biodegradability, and some by-products of ozonised nitrophenols. Ad Environ Res 8:303-311

36. Zhai X, Chen Z, Zhao S, Wang H, Yang L (2010) Enhanced ozonation of dichloroacetic acid in aqueous solution using nanometer $\mathrm{ZnO}$ powders. J Environ Sci 22:1527-1533

37. Tong S, Shi R, Zhang $\mathrm{H}$, Ma C (2011) Kinetics of $\mathrm{Fe}_{3} \mathrm{O}_{4}-\mathrm{CoO} /$ $\mathrm{Al}_{2} \mathrm{O}_{3}$ catalytic ozonation of the herbicide 2-(2,4-dichloro phenoxy) propionic acid. J Hazard Mater 185:162-167

38. Martins RC, Quinta-Ferreira RM (2009) Catalytic ozonation of phenolic acids over a Mn-Ce-O catalyst. Appl Catal B Environ 90:268-277

39. Gottschalk C, Libra JA, Saupe A (2000) Ozonation of water and wastewater. Wiley-VCH Publisher, New York

40. Shokri A (2016) Degradation of 4-nitrophenol from industrial wastewater by nano catalytic ozonation. Int $\mathrm{J}$ Nano Dimens $7: 160-167$ 